\title{
Efficacy of the Secondary Education Development and Improvement Project (SEDIP) in Biliran Division, Philippines
}

\author{
Christopher R. Vicera \& Armando Laude \\ Naval State University, Naval, Biliran, Philippines
}

\begin{abstract}
The efficacy of the Secondary Education Development and Improvement Project (SEDIP) in Division of Biliran is the focus of this study. It ascertained the perceived extent of implementation of SEDIP components: in-service training, high school innovation fund, secondary schooling alternatives, capability building, textbooks and procurement, and civil works. SEDIP and its components has been implemented "to a large extent" in Biliran Division. Among the subject areas evaluated during the NAT, English has the highest mean percentage score while Science has the lowest. There is a significant difference between the school managers' and teachers' perceptions, NAT MPS during the four-year period and a significant relationship between the perceived extent of SEDIP and the NAT MPS implementation. Problems related to the implementation of the SEDIP components are "moderately felt" by the school managers and teachers.
\end{abstract}

Keywords: Effectiveness, Public Secondary Education Development and Improvement Project

\section{Introduction}

The efficacy of the Secondary Education Development and Improvement Project (SEDIP) in Division of Biliran is the focus of this study. It also ascertained the perceived extent of implementation of SEDIP components: in-service training, high school innovation fund, secondary schooling alternatives, capability building, textbooks and procurement, and civil works. Moreover, SEDIP and its components has been implemented "to a large extent" in Biliran Division. Among the subject areas evaluated during the NAT are English has the highest mean percentage score and Science has the lowest. It further has a significant difference between the school managers' and teachers' perceptions, NAT MPS during the four-year period and a significant relationship between the perceived extent of SEDIP and the NAT MPS implementation. Furthermore, Problems related to the implementation of the SEDIP components are "moderately felt" by the school managers and teachers.

Education as an ever continuing process is the sum of learning experiences acquired by an individual inside or outside the school. It consist of formal learning obtains from school and the actual experiences and interactions formally acquires at home and in other places outside of the school. It is also the primary and utmost concern of every civilized society. Its impact on the economy, manpower and progress of any country is left with no doubt and the primary reason why most countries are resolved to provide the most appropriate and complete education for their people.

Over the years, the call for relevance and quality has been recurring issue that educational institutions must address. While the word "relevance" and "quality" mat have been interpreted in various context and dimensions, a common ground that educational system must respond effectively in the changing needs and conditions of existing contemporary society. Efforts has been focused towards formulating educational innovations to address such relevance and quality issues. So that the Secondary Education Development and Improvement Project (SEDIP in the Department of Education came into being. (Bernadas, 2006)

SEDIP, as sited in the SEDIP-HSIF Operations Manual (2004) is one of the foreign-assisted projects executed by the Department of Education through the Bureau of Secondary Education to improve the learning achievement in public secondary schools and enhance the attainment of the Philippine National Educational goals as enunciated in the Education for All and the Philippine national Development documents. As loan assistance package it aim to improve equitable access to quality secondary education in 26 Social Reform Agenda provinces. The project is co-financed by the Asian Development Bank (ADB) and Japan Bank for International Cooperation (JBIC). (SEDIP Manual, 2004)

The Department of Education (DepEd) exercises responsibility for the implementation of SEDIP. A National Project management Office (NPMO) oversees the day-to-day operation and management of the project and is attached to the Bureau of Secondary Education. Being one among the SRA provinces, the province of Biliran, which is situated in Northwestern part of Region VIII, is one of the recipient and active implementers of the project.

Prior to the implementation of SEDIP in Biliran, the Academic performance of secondary schools, as indicated in their mean percentage scores (MPS), manifested the widening achievement gap compared to other Division in Region VIII. In general, the Division Report Card (DRC) reveals that MPS for the secondary 
schools remain below the national average. Similar document also reveals a fluctuating result of NAT. One of the factors causing the low academic achievement of the secondary schools is lack of science laboratories, libraries and other ancillary facilities. Some schools have identified teaching competence along with the inadequate knowledge of content in science and mathematics as a problem, while others identified management skills/competence of the school head. Hence the need to address such predicament that confronted the division through appropriate interventions like SEDIP.

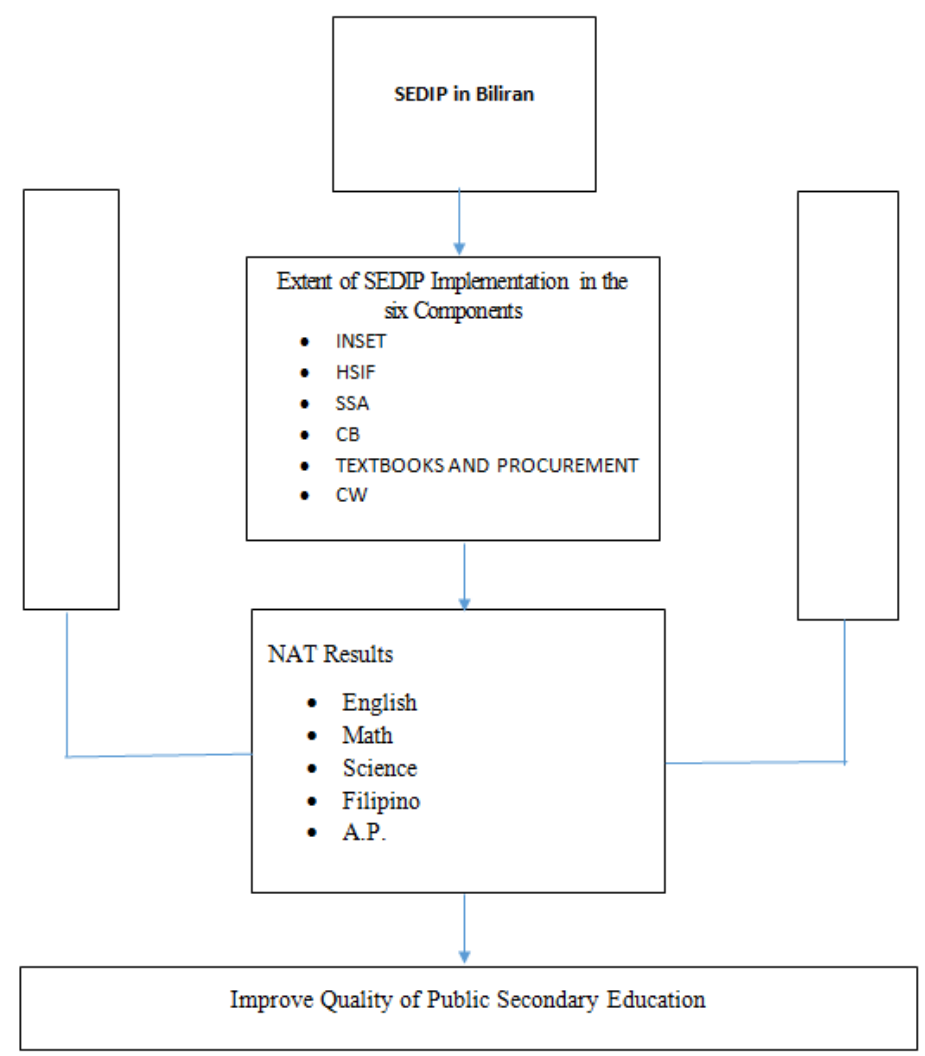

Figure 1: Conceptual framework of the study

\section{Theoretical and Conceptual Framework}

This study is anchored on the theory of Herzberg the two-factor Theory of Motivation, advocated that it is good to study the work environment carefully so that the factors that motivated an individual to high performance can be identified. He theorized that the factors which can lead to high performance can be group into hygiene factors which make people survive in the organization, such as salaries, organization policies, job security, interpersonal relationship, supervision and working condition and motivation factors such as achievement, recognition, work itself, responsibility and advancement. These factors are inherent in the job and when they are present, they will lead to job satisfaction. In Hellriegel, four factors of performance showed that the value of reward is important since a person places benefits to be obtained from a job such as friendship of co-workers, promotion a good salary, or a feeling of accomplishment. Employee effort is the art to perform a job tasked, in other words, how hard the employee is trying, and whether the effort results in and out is a measure of performance. Individuals mastery of the skills to do a job such as conceptual, technical and communications skills while characteristics that can affect a person's job performance is based on the traits. On the other hand, role perception determines how employees define their job and the type of efforts they believe are essentials to effective performance.

The conceptualization of the research basically evolved in the effectiveness of the Secondary Education Development and Improvement Project (SEDIP) in Division of Biliran. This was determined by the perceptions of school managers and teachers on the extent of SEDIP implementation on the six components. This study also ascertained the assessment of NAT and MPS of English, math, Science, Filipino and Araling Panlipunan learning areas. It also determine the significance difference between the school manager and teachers perceptions on the extent of SEDIP implementation. It further ascertained the significant difference in the NAT MPS during the four-year of implementation and the perceived extent of SEDIP implementation and the NAT MPS. Furthermore, it characterized the problems met by the school manager and teachers on the SEDIP implementation. 


\section{Methodology}

This study utilizes the descriptive survey research it described the perceptions of the school managers and teachers on the extent of the SEDIP components implementation and the comparison of seco0nd year student's performance in the four period results of national Achievement Test in the core subject areas tested. This study covered all the 16 secondary schools in Biliran Division. All secondary schools found in each municipality were directly under the supervision of the Schools Division Superintendent. The main data gathering instrument used in this research was a survey questionnaire on the effectiveness of the implementation of SEDIP in Biliran It detailed manifestation on the extent of implementation for each component and the problems met along each component's implementation, as perceived by the subject involved in this study. The data gathered by means of survey questionnaire were interpreted and analyzed using the descriptive statistics, such as analysis of variance, Pearson $\mathrm{r}$ and T-test are the most appropriate statistical measures. Similarly, means of scores obtained using the Likert scales were used to assess the effectiveness on the SEDIP implementation. The analysis and interpretation of data were done $i 9 n$ narrative and tabular forms.

\section{Extent of SEDIP Components Implementation}

\section{Results And Discussion}

The school managers and teachers perceived the six SEDIP components as implemented to a large extent even if their mean values varied from one another. They had common perceptions interpreted as "to a large extent" on the level of the six SEDIP components implementation. This suggests that the objectives of the project has been attained. There was a significance difference on the extent of SEDIP implementation between the perceptions of school managers and teachers. Hence the hypothesis that "there is no significant difference between school managers and teachers' perceptions" is rejected

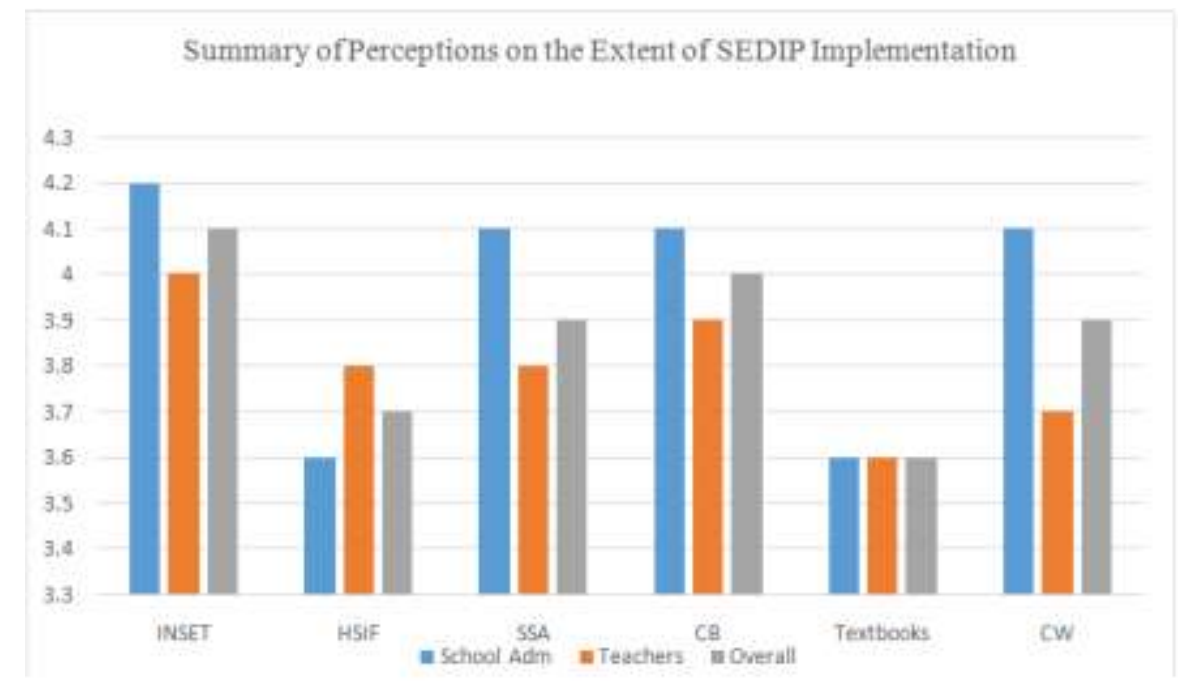

\section{National Achievement Test Results}

The F-ratio on the difference of NAT results among students in five subjects areas. Such as English, Math, Science, Filipino and Araling Panlipunan of 697.82 was interpreted as significance when tested at 5\% probability level. The null hypothesis that "there is no significant difference in the NAT MPS during the fouryear period of SEDIP implementation was rejected. The students got higher mean score in English than any other subject areas especially in Science where they got low mean scores. This was the trend within the four period of assessment. It showed therefore, that students had difficulty in Science far behind the standard passing of 75 percent. The mean of SEDIP implementation was 3.9 and NAT MPS was 57.76 with $\mathrm{r}=.92$ which indicated a very high degree of relationship. The computed $r$ value was 4.72 and was greater than the table value of 4.604. The null hypothesis tested was rejected at .05 level.

\section{Problems Met on SEDIP Implementation}

On the problems met by the school managers and teachers on the SEDIP implementation, the INSET obtained a grand mean of 2.95, HSIF with 2.74, SSA with 2.81, Textbook and Procurement with 2.68, and CW with 2.83 all interpreted as "moderately felt problem". However, on CB implementation, both school managers and teachers had different grand mean of 2.41 which was interpreted as "slightly felt problem." The general perceptions of "moderately felt problem" was evident along the SEDIP components implementation by both school managers and teachers. 


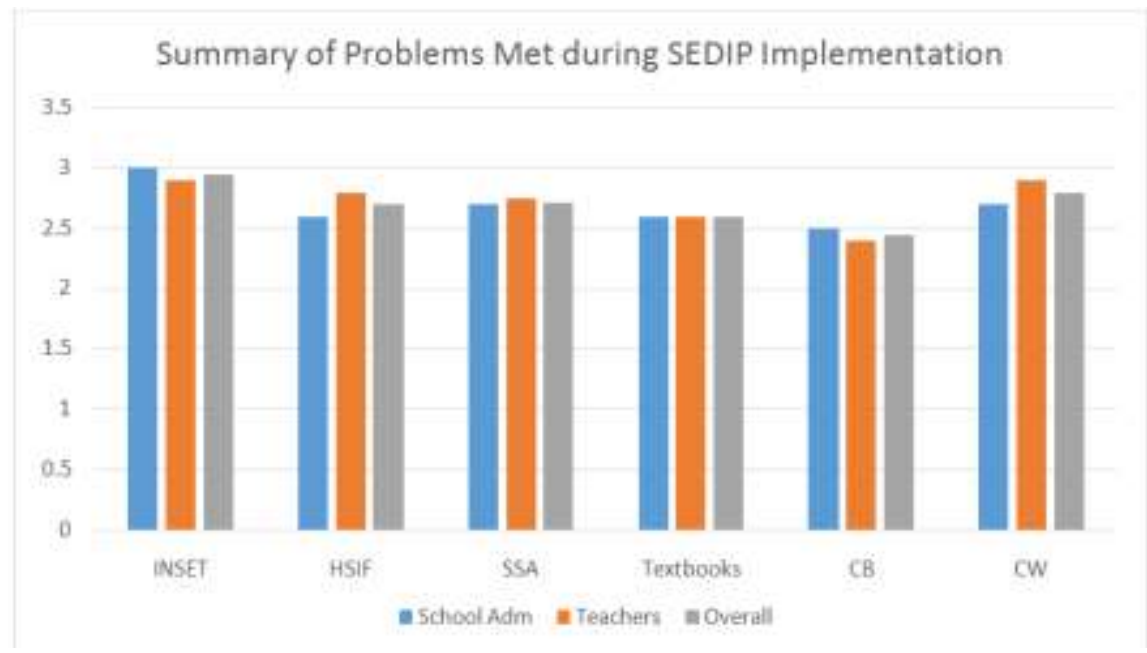

\section{Conclusion}

The Secondary Education Development Project (SEDIP), including its six component programs, has been implemented "to a large extent" in Biliran Division. English has the highest mean percentage score while Science has the lowest MPS among the subject areas evaluated during the National Achievement Test. There are significant differences between the school managers and teachers' perception and NAT MPS during the fouryear period of SEDIP implementation in Biliran Division. A significant relationship between the perceived extent of SEDIP implementation and the NAT MPS. Problems related to the implantation of - the SEDIP components are "moderately felt" by the school administrators and teachers.

\section{References}

[1]. Bernadas, Carmelino P. (2006). The Implementation of the Third Elementary Education Project (TEEP) in the Division of Biliran. Unpublished Dissertation Eastern Visayas State University Tacloban City

[2]. Cañete, Alma (2003). Characteristics and Academic Achievement of the Third Elementary Education Project Leader and NonLeader Schools in Biliran Division. Unpublished Dissertation Eastern Visayas State University, Tacloban City

[3]. EDCOM Report. (1993) Making Education manageable, Handouts, Educators' Congress, Baguio City.

[4]. Hellriegel Don and Sown John. (1980) Management, New York, Addison Publishing Company $6^{\text {th }}$ Edition

[5]. Herzberg, Frederick, et al (1980) The Motivation at Work, New York, John Willy and Sons, Inc.

[6]. Lapus, Jeslie (2006). Education News, Volume 2 No. 10.

[7]. Leiberman, Ann. (1986). Collaborative Work, Educational leadership, Volume 43 No. 5.

[8]. SEDIP-HISIF Operations Manual (2004).

[9]. Simon, Herbert. (1980). Leadership Organization, Chicago, University of Chicago Press. 